\title{
Antigerminative Effects of Ethanolic Crude Extracts from devil tree (Alstonia scholaris) on Seed Germination and Seedling Growth against Selected Plants
}

\author{
Sawatdikarn Sanit ${ }^{1}$
}

\begin{abstract}
${ }^{1}$ Department of Applied Science, Faculty of Science and Technology, Phranakhon Si Ayutthaya Rajabhat University, Phranakhon Si Ayutthaya, Thailand
\end{abstract}

\begin{abstract}
The study of ethanolic crude extracts from the leaves of devil tree (Alstonia scholaris) were extracted by $95 \%$

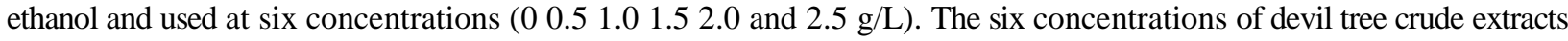
were tested on the inhibitory on seed germination and seedling growth of six tested crops (mimosa (Mimosa pigra), chinese kale (Brassica oleracea), amaranthus (Amaranthus viridis), barnyard grass (Echinochloa crus-galli), weedy rice (Oryza sativa) and waxy corn (Zea mays). Inhibitory of five characteristics (seed germination, shoot length, root length, seedling fresh weight and seedling dry weight) were recorded. The results showed that all crude extracts of devil tree

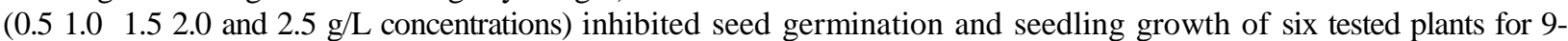
$100 \%$ inhibition. whereas, the devil tree crude extracts at $2.5 \mathrm{~g} / \mathrm{L}$ concentration showed the highest inhibition of seed germination and seedling growth in term of shoot length, root length, seedling fresh weight and seedling dry weight characteristics at $100 \%$ inhibition against three tested plants (mimosa, chinese kale as well as amaranthus). A raise of concentration of devil tree crude extracts showed increased inhibition of seed germination and seedling growth in six tested plants. The result is showed the antigerminative effects of devil tree (A. scholaris) as well as suggested that the utilization of the ethanolic crude extracts from the leaves of devil tree (A. scholaris) so as to weed management.
\end{abstract}

Keywords: Ethanolic Crude Extracts, Devil Tree, Seed Germination Inhibition, Seedling Growth Inhibition, Antigerminative Effects

\section{Introduction}

Allelopathic activity is the mechanism of the interaction between life communities (crop species and weed species) in environmental condition (Sawatdikarn, 2020). Allelopathic activity in the environmental conditions comprise four groups of interaction included crop-crop species interaction, crop-weed species interaction, weed-crop species interaction and weed-weed species interaction (Sawatdikarn, 2017).

The allelochemical substances released from the dornor plants affected to the receive plants. (Chengxu et al., 2011). Allelochemical substances caused to allelopathic activity (Julio et al., 2019). Several crops and weeds have strong allelopathic activity, For example of some crops namely sorgoleone is the most allelochemical compound of sorghum (Sorghum bicolor) exuded by root plants (Jabran et al., 2015). The phenolic acid is the most allelochemical compound of sunflower (Helianthus annuus) exuded by leaves and stems parts (Naseem et al., 2009) the phenolic compounds included hydoxy benzoic acid, genistic acid, cafffeic acid and ferulic acid are the main allelochemical compound from tuber of purple nut sedge (Cyperus rotundus) (Ameena et al., 2015) as well as momilactone A and momilactone B are the most allelochemical compounds of rice (Oryza sativa) induced by leaves plants (Amb and Ahluwalia, 2016).

Some weeds showed the strong allelopathic activity. The phenolic compound is the most allelochemical substance of purslane (Portulaca oleracea) induced by seeds parts (Shehata, 2014). The three groups of compound (phenolics alkaloids and amino acids) are the main allelochemical substance of Chromalaena odorata induced by leaves and stems parts (Rusdy et al., 2015) as well as the four groups of phytochemical compounds (flavonoids, alkaloids tannins and triterpenoids) ) are the main allelochemical substance of Lantana camara induced by leaves parts (Julio et al., 2019). Similarly, Modern of weed management have succeeded due to the integration of allelochemical substances and application of allelopathic activity for weed management.

For the allelopathic activity as the focused for weed management in the several research papers, For the example, Iqbal and Cheema (2008) noted that the 
allelopathic activity of sorghum (Sorghum bicolor) to inhibited of the seedling growth interm of leaf area and plant height in purple nut sedge (Cyperus rotundus). Sawatdikarn (2010) showed that the crude extract from the seeds of three medicinal plants (tree basil (Ocimum gratissimum), celery (Apium graveolens) and dill (Anethum graveolens)) inhibited on seedling growth for $100 \%$ inhibition in purple nutsedge (Cyperus rotundus). Nekonam et al., (2014) noted that the allelopathic effects of six medicinal plants namely Crocus sativus, Ricinus communis, Nicotiana tabacum, Datura inoxia, Nerium oleander and Sorghum bicolor against redroot pigweed (Amaranthus retroflexus). ElShora et al., (2016) exhibited that the allelopathic effects of Zygophyllum coccineum to inhibited of the seed germination and radicle length in Chenopodium album. as well as Ayeni (2017) impressed that the allelopathic potential of leaves from two crops (Senna siamea as well as Pinus carribaea) inhibited of the seed germination and seedling growth in Euphorbia heterophylla.

Lack of the information of allelopathic activity of the ethanolic crude extracts from leaves of devil tree $(A$. scholaris) caused on seed germination and seedling growth characteristics (seed germination, shoot length, root length, seedling fresh weight and seedling dry weight) in six tested plants. The objective of this research was to evaluate of the antigerminative effects of leaves ethanolic crude extracts in devil tree (A. scholaris) on the inhibitory seed germination and seedling growth of six tested crops namely mimosa $(M$. pigra), chinese kale (B. oleracea), amaranthus (A. viridis), barnyard grass (E. crus-galli), weedy rice (O. sativa) and waxy corn (Z. mays).

\section{Materials and Methods Location}

This experiment was conducted at Department of Applied Science, Faculty of Science and Technology, Phranakhon Si Ayutthaya Rajabhat University, Phranakhon Si Ayutthaya province, Thailand during 2019-2020.

The plants in this study namely; devil tree (A. scholaris), mimosa $(M$. pigra $)$, chinese kale $(B$. oleracea $)$, amaranthus (A. viridis), barnyard grass (E. crus-galli), weedy rice ( $O$. sativa) and waxy corn (Z. mays) were collected from the crop fields $\left(14^{\circ} 21^{\prime} \mathrm{N}, 100^{\circ} 34^{\prime}\right.$ E) for three locations (Bangban, Wangnoi and Bangsai) in Phranakhon Si Ayutthaya Province, Thailand, in January 2019.

\section{Preparation of extracts}

The preparation of extracts; The fresh leaves of devil tree (A. scholaris) were chopped into $0.5 \mathrm{~cm}$ long pieces (Sawatdikarn, 2010). The components of fresh leaves of devil tree (A. scholaris) were then over dried at $80^{\circ} \mathrm{C}$. for $3-5$ days and then were ground into powder. One hundred grams of each dried material was extracted with $95 \%$ of ethanol treatment for $48 \mathrm{~h}$ at $25^{\circ} \mathrm{C}$. (Sawatdikarn, 2017).

The plants extracts were respectively filtered through four layers of cheesecloth and centrifuged at 3,000 rpm for $5 \mathrm{~h}$. These extractions were distilled several times by filter papers. Fresh stock extracts were kept in a chamber set at $5^{\circ} \mathrm{C}$. until use.

The bioassay was conducted with six concentrations (l $\begin{array}{lllll}0 & 0.5 & 1.0 & 1.5 & 2.0\end{array}$ and $2.5 \mathrm{~g}$ dry weight equivalent extract/L) of devil tree (A. scholaris) crude extracts.

\section{Seed bioassay}

Seed germination tests and seedling growth tests were conducted for six test plants (mimosa (M. pigra), chinese kale (B. oleracea), amaranthus (A. viridis), barnyard grass (E. crus-galli), weedy rice (O. sativa) and waxy corn (Z. mays)) ; 25 seeds were surface sterilized with $5 \%(\mathrm{w} / \mathrm{v})$ sodium hypochlorite solution for 10 min, rinsed two times with distilled water. 25 seeds six test plants (mimosa (M. pigra), chinese kale ( $B$. oleracea), amaranthus (A. viridis), barnyard grass ( $E$. crus-galli), weedy rice $(O$. sativa) and waxy corn $(Z$. mays)) were put on two layer filter paper in $12-\mathrm{cm}$ petri dishes (Sawatdikarn, 2017).

The seed bioassay was divided into six concentrations $\left(\begin{array}{llll}0 & 0.5 & 1.0 & 1.5 \\ 2.0\end{array}\right.$ and $2.0 \mathrm{~g}$ dry weight equivalent extract/L) of devil tree (A. scholaris) crude extracts. Seed germination tests were tested follow by ISTA (2003) as well as seedling growth tests were tested follow by AOSA (2002). The petri dishes were tested in the darkness at $25^{\circ} \mathrm{C}$. The seed germination was measured at 5 days after incubation in darkness at $25^{\circ} \mathrm{C}$. (AOSA, 2002).

The shoot and root length of seedling was measured at 7 days after incubation in darkness at $25{ }^{\circ} \mathrm{C}$. (AOSA, 2002). The control seeds were tested on the filter paper moistened with the water solution (without the extract). The bioassay was repeated four times with ten plants of each treatment.

The parameter of seed germination and seedling growth divided into five characteristics including seed germination, shoot length, root length seedling fresh weight and seedling dry weight. The seed germination and seedling growth inhibition (M) with respect to the control treament was calculated from the formula (Sawatdikarn, 2017) as follows;

$\mathrm{M}=[(\mathrm{A}-\mathrm{B}) / \mathrm{A}] \mathrm{x} 100$

Where $A$ is the seed germination and seedling growth of the control treament and B is the seed germination and seedling growth of the treated of crude extracts. 


\section{Statistical analysis}

All experiments were done for four replications. Data of five characteristics (inhibitory of seed germination, inhibitory of shoot length, inhibitory of root length, inhibitory of seedling fresh weight and inhibitory of seedling dry weight) of each tests plants (mimosa $(M$. pigra), chinese kale (B. oleracea), amaranthus (A. viridis), barnyard grass (E. crus-galli), weedy rice $(O$. sativa) and waxy corn ( $Z$. mays)) were subjected to analysis using Duncan 's Multiple Range Tests (DMRT).

\section{Results and dicussion}

The leaves of crude extract of devil tree (A. scholaris) at different concentrations $\left(\begin{array}{lllll}0.5 & 1.0 & 1.5 & 2.0\end{array}\right.$ and 2.5 $\mathrm{g} / \mathrm{L})$ showed inhibition on seed germination and seedling growth interm of shoot length, root length seedling fresh weight and seedling dry weight of six tests plants (mimosa (M. pigra), chinese kale (B. oleracea), amaranthus (A. viridis), barnyard grass $(E$. crus-galli), weedy rice (O. sativa) and waxy corn ( $Z$. mays)) for 9-100\% inhibition (Figure 1).

The effect of crude extract of devil tree against mimosa (M. pigra); The crude extracts from the leaves of devil tree at all concentrations ( $\begin{array}{llll}0.5 & 1.0 & 1.5 & 2.0\end{array}$ and $2.5 \mathrm{~g} / \mathrm{L}$ ) inhibited of seed germination and seedling growth (shoot length, root length seedling fresh weight and seedling dry weight in mimosa for 22$100 \%$ inhibition (Figure 1A). The incresed of concentrations of devil tree crude extract as incresed of inhibition on seed germination and seedling growth in mimosa.

The devil tree crude extracts at $2.5 \mathrm{~g} / \mathrm{L}$ concentration exhibited that the highest inhibition of seed germination and seedling growth in term of shoot length, root length, seedling fresh weight and seedling dry weight characteristics at $100 \%$ inhibition against mimosa plant.

Similarly, the allelopathic effects of devil tree (A. scholaris) crude extracts were also reported by Javaid et al. (2010) exhibited that the allelopathic potential of the leaves extract from devil tree (A. scholaris) inhibited of seed germination and seedling growth (shoot length root length and fresh biomass) against pathenium weed (Parthenium hysterophorus).

Besides, Sawadikarn et al. (2011) noted that the allelopathic activity from leaves of devil tree (A. scholaris) inhibited on seed germination and seedling growth against some tested plants namely mungbean (Vigna radiata) and black gram (Vigna mungo).

The leaves of devil tree (A. scholaris) contained alkaloids which known that the allelopathic effects for weed management (Javaid et al., 2010). In addition, alkaloids as some phytochemical substances from the leaves of devil tree (A. scholaris) showed reduction of seed germination and seedling growth in some tested plant species (Sawadikarm et al., 2011).

The effect of crude extract of devil tree against chinese kale (B. oleracea); The crude extracts from the leave of devil tree (A. scholaris) at all concentrations $\left(\begin{array}{llll}0.5 & 1.0 & 1.5 & 2.0\end{array}\right.$ and $2.5 \mathrm{~g} / \mathrm{L}$ ) showed inhibition on seed germination and seedling growth interm of shoot length, root length seedling fresh weight and seedling dry weight against chinese kale ranged from 15 to 100 $\%$ inhibition (Figure 1B). The addition of concentration of devil tree (A. scholaris) crude extracts as incresed of inhibition on seed germination and seedling growth (shoot length, root length, seedling fresh weight and seedling dry weight) in chinese kale.

For the devil tree crude extracts at $2.5 \mathrm{~g} / \mathrm{L}$ concentration, showed that the highest inhibition of seed germination and seedling growth in term of shoot length, root length, seedling fresh weight and seedling dry weight characteristics at $100 \%$ inhibition against chinese kale

The data is agreement with the results of Wang et al. (2014) who showed that the effective allelopathic activity of devil tree (A. scholaris) crude extracts against four tested plants (Bidens pilosa, Lactuca sativa and Brassica chinensis) as well as Sawadikarn et al. (2011) impressed that the allelopathic potential from bark and leaves of devil tree (A. scholaris) inhibited on seed germination and seedling growth against chinese kale. These data exhibited the allelopathic potential from leaves of devil tree (A. scholaris) against chinese kale.

The effect of crude extract of devil tree against amaranthus (A. viridis); The crude extracts of devil tree (A. scholaris) at all concentrations (0.5 1.01 .5 2.0 and $2.5 \mathrm{~g} / \mathrm{L}$ ) exhibited inhibition on seed germination and seedling growth interm of shoot length, root length seedling fresh weight and seedling dry weight against amaranthus ranged from 9 to $100 \%$ inhibition (Figure 1C). The increasing of concentration of devil tree (A. scholaris) crude extracts as addition of inhibition on seed germination and seedling growth for five characteristics (shoot length, root length, seedling fresh weight and seedling dry weight) against amaranthus.

The devil tree crude extracts at $2.5 \mathrm{~g} / \mathrm{L}$ concentration exhibited that the highest inhibition of seed germination and seedling growth in term of shoot length, root length, seedling fresh weight and seedling dry weight characteristics at 100\% inhibition against amaranthus (Figure 1C).

These data showed the allelopathic activity from leaves 
of devil tree (A. scholaris) against amaranthus (A. viridis). Some researchers noted that the allelopathic activity from leaves of some plant tree species can be management for the aggressive weeds as well as the plant disease control. The study of allelopathic activity from leaves of the three plant tree species namely Azadiracthta indica, Melia azedarach and Mangifera indica can be management for parthenium weed (Parthenium sp.) (Dukpa et al., (2020) as well as the study of antimicrobial activity from some leaves of the six plant tree species namely Acacia nilotica, Alstonia scholaris, Azadiracthta indica, Melia azedarach, Ficus bengalensis and Mangifera indica can be management for seed-borne disease (Alternaria alternata and Fusarium solani) (Shafique et al., 2007).

Besides, Wang et al. (2014) who showed that the effective allelopathic activity of devil tree (A. scholaris) crude extracts against four tested plants (Bidens pilosa, Lactuca sativa and Brassica chinensis). The crude extract of devil tree showed the allelopathic activity and antimicrobial activity because the crude extracts contained some phytochemical substances as alkaloids as well as the alkaloids caused reduction of seed germination and seedling growth against some tested plants (Dukpa et al., (2020), In addition, the alkaloids from the leaves of devil tree (A. scholaris) exhibited the reduction of sporulation mechanisms and reduction of mycelial growth of some pathogens (Shafique et al., 2007).

The effect of crude extract of devil tree against barnyard grass (E. crus-galli); The crude extracts from the leave of devil tree (A. scholaris) at all concentrations ( $\left(\begin{array}{llll}0.5 & 1.0 & 1.5 & 2.0\end{array}\right.$ and $\left.2.5 \mathrm{~g} / \mathrm{L}\right)$ showed inhibition on seed germination and seedling growth interm of shoot length, root length seedling fresh weight and seedling dry weight against chinese kale ranged from 15 to $95 \%$ inhibition (Figure 1D). The addition of concentration of devil tree (A. scholaris) crude extracts as incresed of inhibition on seed germination and seedling growth (shoot length, root length, seedling fresh weight and seedling dry weight) in barnyard grass. The devil tree crude extracts at $2.5 \mathrm{~g} / \mathrm{L}$ concentration showed that the peakest inhibition of seed germination and seedling growth in term of shoot length, root length, seedling fresh weight and seedling dry weight characteristics ranged from $86 \%$ to $95 \%$ inhibition against barnyard grass (Figure 1D).

This results noted that the allelopathic effects of devil tree (A. scholaris) crude extracts. This data is consistent with the research of Hameed et al. (2020) who showed the the allelopathic effects from leaves of devil tree (A. scholaris) inhibited on seed germination and seedling growth of wheat (Triticum aestivum). The phytochemical compounds from leaves of devil tree
(A. scholaris) crude extracts contained alkaloids compound, these phytochemical compound showed the antigerminative activity and allelopathic activity (Wang et al., 2014).

The effect of crude extract of devil tree against weedy rice $(O$. sativa) ; The crude extracts of devil tree $(A$. scholaris) at all concentrations (lllllll $\begin{array}{llll}0.5 & 1.0 & 1.5 & 2.0\end{array}$ and $2.5 \mathrm{~g} / \mathrm{L})$ showed the inhibition on seed germination and seedling growth (shoot length, root length seedling fresh weight and seedling dry weight) against weedy rice ranged from $12 \%$ to $86 \%$ inhibition (Figure 1E).

The addition of concentration of devil tree ( $A$. scholaris) crude extracts as addition of inhibition on seed germination and seedling growth (shoot length, root length, seedling fresh weight and seedling dry weight) against weedy rice. The devil tree crude extracts at $2.5 \mathrm{~g} / \mathrm{L}$ concentration showed that the strongest inhibition of seed germination and seedling growth (shoot length, root length, seedling fresh weight and seedling dry weight) for $74-86 \%$ inhibition against weedy rice (Figure 1E). This study showed the allelopathic activity of devil tree (A. scholaris) crude extract that is consistent with the research of Sawadikarn et al. (2011) who showed that the allelopathic impaction from bark and leaves of devil tree (A. scholaris) inhibited on seed germination and seedling growth against rice (O. sativa). Similarly, Hameed et al. (2020) who showed the the allelopathic effects from leaves of devil tree (A. scholaris) inhibited on seed germination and seedling growth interm of plant height, shoot fresh weight, shoot dry weight, root fresh weight and root dry weight against wheat (Triticum aestivum).

The phytochemical compounds from leaves of devil tree (A. scholaris) crude extracts contained alkaloids compound, these phytochemical compound showed the antigerminative activity and allelopathic activity (Wang et al., 2014).

For the effect of crude extract of devil tree against waxy corn (Z. mays); The crude extracts of devil tree (A. scholaris) at all concentrations (0.5 $1.0 \quad 1.52 .0$ and $2.5 \mathrm{~g} / \mathrm{L})$ showed the inhibition on seed germination and seedling growth (shoot length, root length seedling fresh weight and seedling dry weight) against waxy corn between $11-81 \%$ inhibition (Figure $1 \mathrm{~F})$. The increasing of concentration of devil tree $(A$. scholaris) crude extracts as addition of inhibition on seed germination and seedling growth against waxy corn.

The devil tree crude extracts at $2.5 \mathrm{~g} / \mathrm{L}$ concentration exhibited that the highest inhibition of seed germination and seedling growth for $69-81 \%$ inhibition against waxy corn (Figure 1F). The devil tree $(A$. scholaris) crude extracts showed the antigerminative 
activity and allelopathic activity against waxy corn that is agreement with the results of Sawadikarn et al. (2011) who impressed that the allelopathic activity from bark and leaves of devil tree (A. scholaris) inhibited on seed germination and seedling growth against some tested plants namely rice, corn and chinese kale.

The phytochemical compounds from leaves of devil tree (A. scholaris) crude extracts contained alkaloids compound (Wang et al., 2014). and triterpenes (ElAskary et al., 2012). These phytochemical compound (alkaloids compound as well as triterpenes) showed the antigerminative activity and allelopathic activity against three tested plants (Bidens pilosa, Lactuca sativa and Brassica chinensis). (Wang et al., 2014). Besides, the devil tree (A. scholaris) crude extracts showed the allelopathic activity against some tested plants (El-Askary et al., 2012).

In the same way, Azhar et al. (2016) who showed the antimicrobial effects of alkaloids from devil tree $(A$. scholaris) against Fusarium solani (the pathogen of fusarium wilt disease). The leaves of devil tree ( $A$. scholaris) showed the antimicrobial activity and allelopathic activity because of several phytochemical compound namely alkaloids (Zhou et al., 2005; Arulmozhi et al., 2007) steroids (Pratyush et al., 2011) triterpenoids (Wang et al., 2009) and phenolic compound (Pratyush et al., 2011).

The phytotoxic effects and allelopathic activity from the leaves of devil tree (A. scholaris) crude extracts showed the inhibitory of seed germination and seedling growth (seed germination and seedling growth in term of shoot length, root length seedling fresh weight and seedling dry weight characteristics) against six tested plants (mimosa (Mimosa pigra), chinese kale (Brassica oleracea), amaranthus (Amaranthus viridis), barnyard grass (Echinochloa crusgalli), weedy rice (Oryza sativa) and waxy corn (Zea mays).

These results have been confirmed by several researches that study of antigerminative activity and allelopathic activity of devil tree (A. scholaris) crude extracts against some tested plants, For examples, The alkaloids compound from the leaves of devil tree (A. scholaris) showed the allelopathic activity (Pratyush et al., 2011). In addition, Sawatdikarn et al. (2011) noted that the allelopathic activity from the leaves of devil tree (A. scholaris) inhibited on seed germination and seedling growth against two tested plants (mungbean as well as black gram). The crude extracts from the leaves of devil tree (A. scholaris) showed the allelopathic effects on seed germination and radicle growth against of two tested plants (Bidens pilosa and Lactuca sativa) (Wang et al., 2014).

Hameed et al. (2020) noted that the allelopathic effects of the crude extracts from the leaves of devil tree $(A$. scholaris) on the stem growth character and root area character in wheat for two choices, the first choice that focused, the crude extracts from the leaves of devil tree (A. scholaris) showed reduction in stem growth and exhibited reduction in root area of wheat as well as the second choice focused, the crude extracts from the leaves of devil tree (A. scholaris) caused the growth retardation of wheat and showed the tissue damage of wheat. Sawatdikarn et al. (2011) impressed that the allelopathic activity from the leaves of devil tree $(A$. scholaris) showed the reduction of percentages of seed germination against mungbean and black gram) as well as the allelopathic activity from the leaves of devil tree $(A$. scholaris) exhibited the reduction of seedling growth interm of tem height, number of leaf, leaf width and leaf length against mungbean and black gram.

These result indicated that the crude extracts of devil tree (A. scholaris) showed the antigerminative activity and exhibited the inhibition on seed germination and seedling growth against some tested plants (mimosa, chinese kale amaranthus barnyard grass weedy rice and waxy corn) divided into two groups upon efficacy of the control of some tested plants, 1) the strongest of crude extracts of devil tree (A. scholaris) against some tested plants, these groups showed the inhibition of seed germination and seedling growth for $100 \%$ inhibition (the completely excellent of inhibition) for three tested plants (mimosa, chinese kale as well as amaranthus) and 2) the weak of crude extracts of devil tree $(A$. scholaris) against some tested plants, these groups showed the inhibition of seed germination and seedling growth ranged from 9-95\% inhibition (the weak of inhibition) for three tested plants (barnyard grass weedy rice as well as waxy corn).

These result impressed that the allelopathic potential of crude extracts in devil tree (A. scholaris) showed the completely excellent of antigerminative activity and exhibited the strongest of inhibition on seedling growth against the three tested plants (mimosa, chinese kale and amaranthus).

These finding revealed that the allelopathic impaction of crude extracts in devil tree (A. scholaris) is the newest application as botanical herbicide had exploited for biological control for weed management (mimosa and amaranthus).

\section{Conclusion}

All crude extracts of devil tree (0.5 1.01 .52 .0 and 2.5 $\mathrm{g} / \mathrm{L}$ concentrations) inhibited seed germination and seedling growth of six tested plants for 9-100\% inhibition. whereas, the devil tree crude extracts at 2.5 $\mathrm{g} / \mathrm{L}$ concentration showed the highest inhibition of seed germination and seedling growth in term of shoot length, root length, seedling fresh weight and seedling dry weight characteristics at $100 \%$ inhibition 
against three tested plants (mimosa, chinese kale as well as amaranthus). A raise of concentration of devil tree crude extracts showed increased inhibition of seed germination and seedling growth in six tested plants. The crude extracts of devil tree at $2.5 \mathrm{~g} / \mathrm{L}$ concentration showed the completely awesome of inhibition of seed germination and seedling growth in term of shoot length, root length, seedling fresh weight and seedling dry weight characteristics (100\% inhibition) against three tested plants (mimosa, chinese kale as well as amaranthus). These result indicated that the crude extracts of devil tree (A. scholaris) showed the completely excellent of antigerminative activity and exhibited the strongest of inhibition on seedling growth against the three tested plants (mimosa, chinese kale and amaranthus).

\section{References}

1. Amb, M. K. and A. S. Ahluwalia. 2016. Allelopathic: potential role to achieve new milestones in rice cultivation. Rice Science. 23:165-183.

2. Ameena, M., A. L. Geethakumari and S. George. 2015 Allelopathic effects of root exudates of purple nut sedge (Cyperus rotundus L.) on growth of field crops. Journal Crop and Weed. 11:142-145.

3. AOSA. 2002. Seed Vigor Testing Handbook. Association of Official Seed Analysts. No.32.

4. Arulmozhi, S., M. P. Mazumder., P. Ahok and L. S. Narayanan. 2007. Pharmacological activities of Alstonia scholaris Linn (Apocynaceae)- A review. PHCOG. Rev. 1:163-170.

5. Ayeni, M. J. 2017. Effect of aqueous extracts of the leaves of Senna siamea Lam. and Pinus carribaea (Jacq.) ex. Walp. on the germination and seedling growth of Euphorbia heterophylla L. World Scientific News. 87:12-23.

6. Azhar, W., Jabeen, K., Iqbal, S. 2016. Appraisal of Alstonia scholaris antifungal activity against fusarium wilt. J. Agric. Res. 54, 221-231.

7. Chengxu, W., Z. Mingxing., C. Xuhui and Q. Bo. 2011. Review on allelopathic of exotic invasive plants. Procedia Engineering. 18:240-246.

8. Dukpa, R., A. Tiwari and D. Kapoor. 2020. Biological management of alleliphathic plant Parthenium sp. Open Agriculture. 5:252-261.

9. El-Askary, H. I., M. M. El-Olemy., M. M, Salama., A. A. Sleem and M. H. Amer. 2012. Bioguided isolation of pentacyclic triterpenes from the leaves of Alstonia scholaris (L.) R. Br. Growing in Egypt. Natural Product Research. 26:1755-1758.

10. El-Shora., Y. A. El-Amier and M. H. Awad. 2016. Antimicrobial activity and allelopathic activity of Zygophyllum coccineum L. on Chenopodium album L.. British Journal of Applied Science \& Technology. 15:1-10.

11. Hameed, M., S. Fatima., S. M. R. Shah., F. Ahmad., M. Ashraf., Maryam., M. S. A. Ahmad., I. Ahmad and U. Iqbal. 2020. Ultrastructural response of wheat (Triticum aesivum L.) lines to potential allelopathy of Alstonia scholaris. Turkish Journal of Botany. 44:509-525.

12. Iqbal, J. and Z. A. Cheema. 2008. Purple nutsedge (Cyperus rotundus L.) management with combined application of sograab and S-metolachlor. Pak. J. Bot. 40:2383-2391.
13. ISTA. 2003. ISTA Handbook on Seedling Evaluation, 3 rd Edition. International Rules for Seed Testing 2003.

14. Jabran, K., G. Mahajan., V. Sardana and B. S. Chauhan. 2015 Allelopathy for weed control in agricultural systems. Crop Protection. 72: 57-65.

15. Javaid, A., S. Shafique., R. Bajwa and S. Shafique. 2010. Parthenium management through aqueus extracts of Alstonia scholaris. Pak. J. Bot. 42:3651-3657.

16. Julio, A., W. C. Tandoc., H. D. Tipace., Y. F. Vendivil., Z. Yanesa., M. V. R. Tare., E. J. Lactoaen and K. J. Clemente. 2019. Allelopathic effect of Lantana camara and Chromolaena odorata leaf extracts on plant germination. Asian J. Agric. \& Biol. 9:190196.

17. Naseem, M., M. Aslam., M. Ansar and M. Azhar. 2009 Allelopathic effects of sunflower water extract on weed control and wheat productivity. Pak. J. Weed Sci. Res. 15:107-116.

18. Nekonam, M. S., J. Razmjoo., H. Kraimmojeni., B. Sharifnabi., H. Amini and F. Bahrami. 2014. Assessment of some medicinal plants for the allelopathic potential against redroot pigweed (Amaranthus retroflexus). Journal of Plant Protection Research. 54: 90-95.

19. Rusdy, M., M. Riadi., A. M. Sari and A. Normal. 2015 Comparative Allelopathic effect of Imperata cylindrical and Chromalaena odorata on germination and seedling growth of Centronema pubescens. International Journal of Scientific and Research publicaations. 5: 1-5.

20. Sawatdikarn, S. 2010. Effects of some crude extracts on inhibition of growth in purple nutsedge (Cyperus rotundus L.), p. 1-6. In Proceeding of The $36^{\text {th }}$ Congress on Science and Technology of Thailand.

21. Sawatdikarn, S. 2017. In vitro allelopathic effects of ethanolic crude extracts from six members in Piper genus on seed germination and seedling growth in Black gram (Vigna mungo Hepper.). p. 89-98. In Proceeding of the International Scientific Conference on Engineering and Applied Sciences.

22. Sawatdikarn, S. 2020. In vitro allelopathic effects of Eehanolic crude extracts from six medicinal herbs on seed germination and seedling growth in black gram (Vigna mungo Hepper.). p. 178-190. In Proceeding of the 7 th Annual Conference on Engineering and Information Technology.

23. Sawatdikarn, S., S. Teanthong., N. Pradabpet., W. Rungprom and S. Siripornvisal. 2011. Crude extraction from bark and leaves of devil tree (Alstonia scholaris) and effect of crude extracts on seed germination and growth of some crops. p. 596606. In Proceeding of 49 th Kasetsart University Annual Conference.

24. Shafique, S., A. Javaid., R. Bajwa and S. Shafique. 2007. Effect of aqueous leaf extracts of allelopathic trees on germination and seed-borne mycoflora of wheat. Pak. J. Bot. 39:2619-2624.

25. Shehata, H. F. 2014. Allelopathic potential of Portulaca oleracea L. seed extracts on germination and seedling growth of Cichorium endivia L., Lactuca sativa L., Echinochloa crus-galli L. and Brassica tournefortii Gouan. Journal of Experimental Biology and Agricultural Sciences. 2:388-396.

26. Wang, C., H. Chen., Y. Li., J. Weng., Y. Jhan., S. Lin and C. Chou. 2014. The role of pentacyclic triterpenoids in the allelopathic effects of Alstonia scholaris. J. Chem. Ecol. 40:9098.

27. Wang, F., F. Ren and J. Liu. 2009. Alstonic acid A and B, unusual 2,3-secofernane triterpenoids from Alstonia scholaris. Phytochemistry. 70:650-654.

28. Zhou, H., H. P. He., S. D. Luo., Y. H. Wang., X. W. Yang., Y. T. Di and X. J. Hao. 2005. Three new indole alkaloids from the leaves of Alstonia scholaris. Helv. Chim. Acta. 88:2508-2512. 
(A)

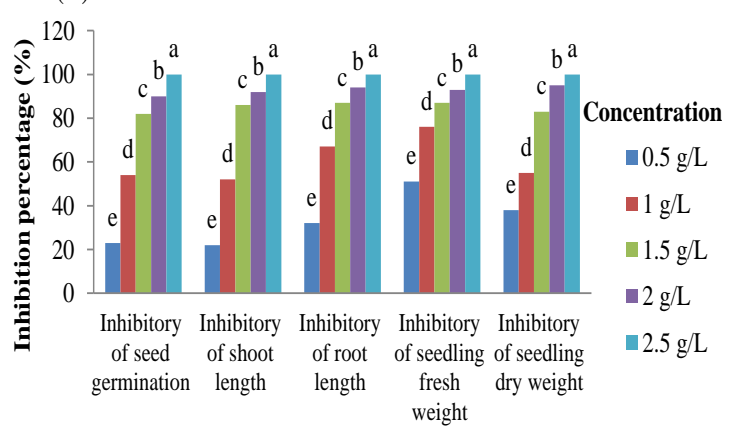

(C)

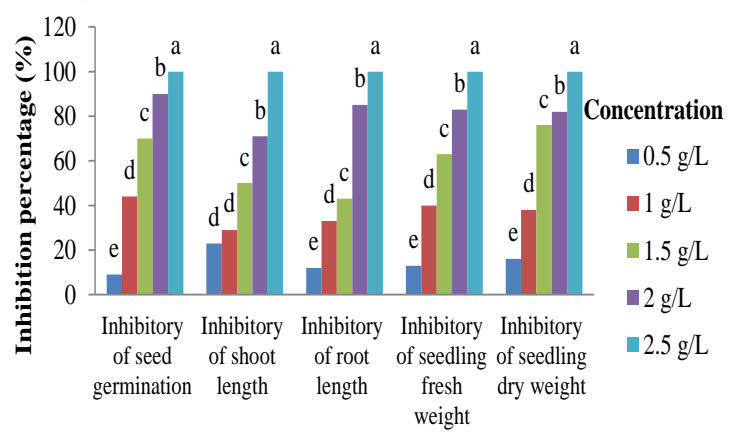

(E)

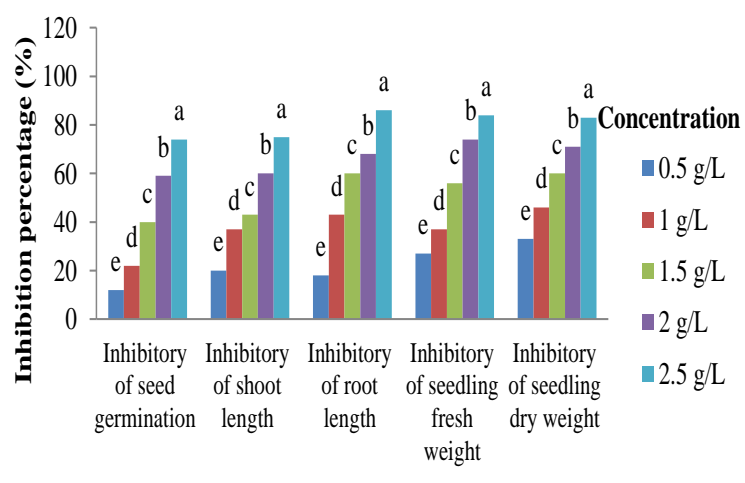

(B)

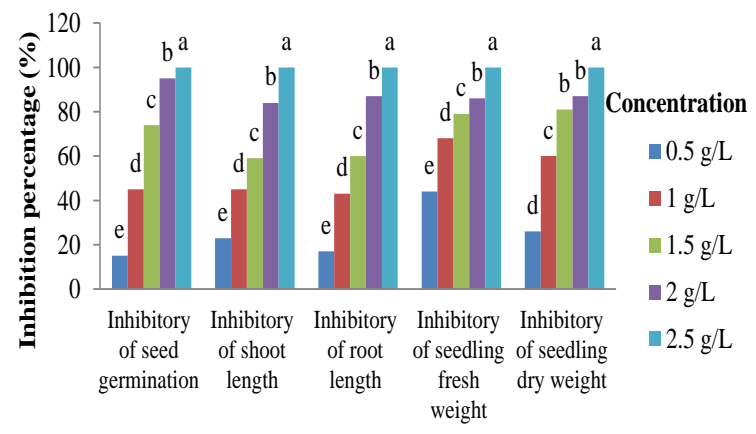

(D)

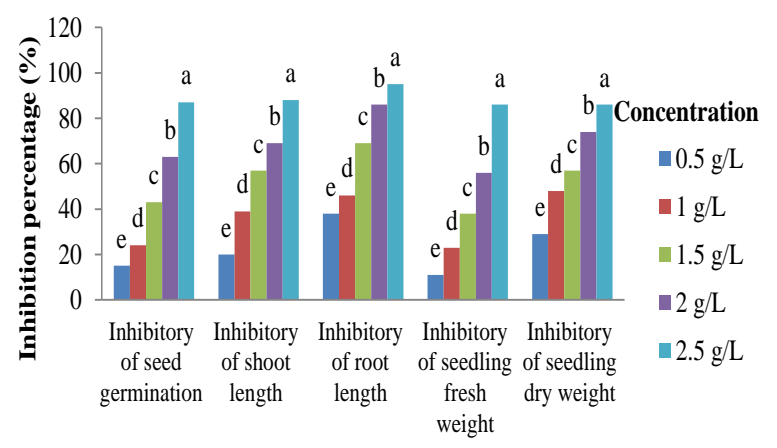

(F)

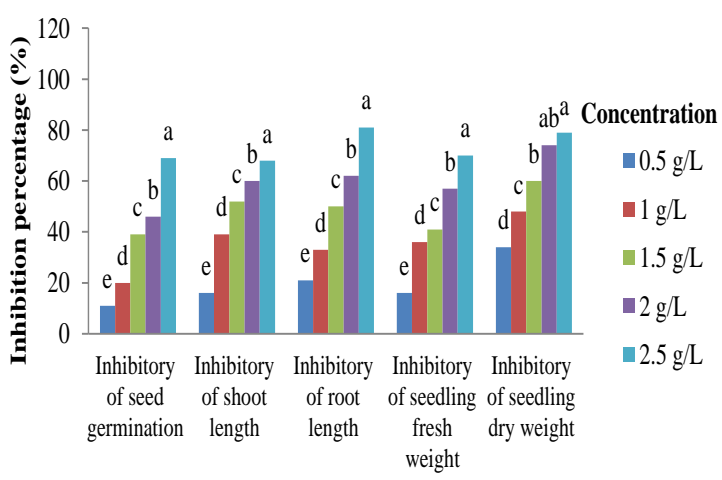

Figure 1. Inhibitory percentage of seed germination, shoot length, root length, seedling fresh weight and seedling dry weight of mimosa (A) chinese kale (B) amaranthus (C) barnyard grass (D) weedy rice (E) and waxy corn (F) as affected by different concentrations of Alstonia scholaris crude extracts.

Values with different letter show significant difference $(\mathrm{p}<0.05)$ as determined by Duncan 's Muntiple Range Test (DMRT). 